Revista de Economia Política, vol. 34, nº 1 (134), pp. 103-119, janeiro-março/2014

\title{
Política industrial e desenvolvimento econômico: a reatualização de um debate histórico
}

\author{
DANIEL ARRUDA CORONEL \\ ANDRÉ FILIPE ZAGO DE AZEVEDO \\ ANTÔNIO CARVALHO CAMPOS*
}

Industrial policy and economic development: a review of the contemporary debate. This paper discusses the importance of the industrial policy for the Brazilian economic development. It presents the theoretical foundations and the main international experiences about this theme. Besides it examines the main industrial policies adopted in Brazil, especially in recent years. Based on this discussion, it is possible to note that despite the criticisms against this policy, they were widely used by many developed countries in the past and also played an important role, contributing to increase the industrial growth in Brazil. However, the recent Brazilian industrial policies were not so efficient, especially when compared with those adopted during most of the $20^{\text {th }}$ century.

Keywords: industrial policy; economic development; Brazilian economy.

JEL Classification: L16; O14.

\section{INTRODUÇÃO}

As políticas industriais são ações e instrumentos utilizados pelos países com o objetivo de fomentar o setor industrial e aumentar as taxas de crescimento econômico, embora seu conceito não apresente uma interpretação consensual na litera-

\footnotetext{
"Respectivamente, Professor Adjunto do Programa de Pós-Graduação em Administração da Universidade Federal de Santa Maria (UFSM) e Doutor em Economia Aplicada pela Universidade Federal de Viçosa (UFV).E-mail: daniel.coronel@uol.com.br; Professor Titular do Mestrado em Economia da Universidade do Vale do Rio dos Sinos (UNISINOS) e Bolsista de Produtividade do Conselho Nacional de Desenvolvimento Científico e Tecnológico (CNPq).E-mail: aazevedo@unisinos.br; Professor Titular do Programa de Pós-Graduação em Economia Aplicada da UFV e Bolsista de Produtividade do CNPq. E-mail: accampos@ufv.br. Os autores agradecem os comentários e sugestões dos professores Luiz Carlos Bresser-Pereira e Pedro Cesar Dutra Fonseca. Os erros e omissões porventura remanescentes são de responsabilidade exclusiva dos autores. Submetido: 4/janeiro/2013; Aprovado: 30/abril/2013.
} 
tura econômica. De acordo com Krugman (1989), política industrial pode ser interpretada como um empenho governamental em fomentar setores avaliados como importantes para o crescimento econômico do país. Ao escolher proteger e estimular determinados setores, em detrimento de outros, os governos estão direcionando suas ações em busca de uma estratégia de desenvolvimento. Em suma, a finalidade da política industrial é promover o desenvolvimento de setores econômicos fundamentais para a geração de divisas, difusão de tecnologias e expansão dos níveis de emprego, colaborando, desta forma, para o aumento da competitividade industrial e impulsionando o uso mais eficaz dos recursos naturais.

As políticas industriais, por mais criticadas que sejam por vários teóricos da economia e pelos governantes de países desenvolvidos, foram utilizadas por várias nações, em diferentes momentos de sua história (Chang, 2002). Segundo esse autor, os países desenvolvidos estariam "chutando a escada", ou seja, utilizaram-se de várias políticas quando ainda não eram desenvolvidos e, atualmente, não querem que os países em desenvolvimento as utilizem, ou seja, mudaram sua postura ao ingressarem no "rol" dos países desenvolvidos.

No Brasil, a primeira ação com o objetivo de proteger o setor industrial, com certa coordenação, ocorreu no governo de Getulio Vargas, com o processo de substituição de importações que teve início na década de 1930. Posteriormente, a estratégia de fomentar o setor industrial materializou-se, de forma ampla, com Juscelino Kubitschek, sendo objetivo do governo o desenvolvimento do setor industrial, com ênfase na indústria de bens de consumo duráveis. A terceira ação ocorreu no governo de Ernesto Geisel, com o II Plano Nacional de Desenvolvimento (II PND). Contudo, em função das crises do petróleo e do cenário internacional desfavorável, o governo não conseguiu alcançar várias das metas e objetivos propostos. $\mathrm{Na}$ década de 1980 , devido às altas taxas de inflação e à elevada dívida externa, o país não priorizou a política industrial. Nos governos seguintes, de Collor de Mello e de Fernando Henrique Cardoso, embora algumas medidas pontuais tenham sido adotadas, tinha-se a concepção de que uma política econômica que promovesse a estabilidade era a melhor forma de o governo fomentar o setor industrial.

Ao assumir a Presidência da República, o governo Lula encontrou um país com estabilidade política e econômica e credibilidade no cenário internacional. Não obstante, o governo tinha vários desafios tais como diminuir o desemprego, o risco país, as dívidas externa e interna, aumentar o crescimento econômico e fomentar o setor industrial. As baixas taxas de crescimento econômico do setor industrial levaram vários economistas e intelectuais, como Bresser-Pereira (2009, 2010, 2011), a apresentarem argumentos de que o Brasil estava iniciando um processo de desindustrialização, ou seja, um processo de queda da participação do setor industrial na constituição do Produto Interno Bruto (PIB).

Neste contexto, como forma de fomentar o setor industrial, o governo Lula lançou, em 2004, a Política Industrial, Tecnológica e de Comércio Exterior (PITCE), a qual, por falta de objetivos bem definidos e conjuntura desfavorável, não atingiu os objetivos a que se propunha. Em 2008, o Governo Federal lançou a Política de 
Desenvolvimento Produtivo (PDP), que tem como objetivos fomentar o setor industrial através de incentivos creditícios, subsídios, isenção e redução de tributos e marcos regulatórios para algumas atividades setoriais.

Seguindo esta temática, este estudo tem como objetivo discutir os fundamentos teóricos das políticas industriais, bem como apresentar as principais experiências internacionais sobre este tema e fazer uma síntese sobre as principais políticas industriais implantadas no país. Para atingir tais objetivos, fez-se uma ampla análise dos objetivos, ações e metas das políticas industriais adotadas na economia brasileira, utilizando-se do arcabouço teórico sobre políticas industriais disponíveis na literatura econômica internacional e nacional.

O artigo está estruturado em quatro seções, além desta introdução. Na segunda seção, faz-se uma discussão teórica sobre os fundamentos das políticas industriais e esboçam-se as principais experiências internacionais; na seção seguinte, faz-se uma análise das principais políticas industriais implantadas no país; na seção quatro, discutem-se as principais medidas de política industrial implantadas recentemente na economia brasileira e, por fim, são apresentadas as principais conclusões.

\section{POLÍTICA INDUSTRIAL: UM TEMA EM DEBATE}

Os argumentos que norteiam o uso de políticas industriais estão associados à ideia de que uma política industrial é condição fundamental para a superação das restrições macroeconômicas ao crescimento econômico e, além disso, de que a atuação do Estado nas questões microeconômicas, em vez de gerar constrangimentos adicionais para a manutenção da estabilidade, pode colaborar para um maior grau de liberdade para a própria política macroeconômica (Kupfer, 2003).

Um argumento bastante aceito a favor das políticas industriais foi formulado por Friedrich List, no século XIX. List (1986), analisando o caso alemão, advogou a favor de uma tarifa elevada contra a importação de bens manufaturados para proteger as indústrias em desenvolvimento. Stuart Mill (1996) também era favorável a esse argumento de proteção à indústria nascente; contudo, recomendava que a proteção se limitasse às indústrias que, inicialmente, não eram capazes de competir com as importações, mas que, com tempo e experiência no ramo, poderiam competir com sucesso nos mercados internacionais. O grande problema por trás do argumento da indústria nascente é a dificuldade em se determinar o momento exato para se retirar a proteção dada a um determinado setor, que, muitas vezes, acaba se perpetuando por longos anos (Greenaway \& Milner, 1993).

Outro argumento favorável à utilização das políticas industriais fundamenta-se na teoria do "second best", ou seja, a teoria do segundo melhor. De acordo com Krugman (1989), uma política sem interferências é desejável em qualquer mercado somente se todos os demais mercados estiverem funcionando de maneira adequada. Caso isto não esteja ocorrendo, uma intervenção do governo pode colaborar para a redução das falhas de mercados, visando ao aumento do bem-estar da sociedade.

A política industrial é um tema controverso, com vários autores, de cunho 
neoclássico, apresentando restrições à sua utilização (por exemplo, Ferreira \& Hamdan, 2003; Pack \& Saggi, 2006; Pinheiro et al., 2007). Esses autores argumentam que as políticas industriais beneficiam poucos setores da economia, ou seja, ao escolher medidas para proteger determinados setores, muitas vezes por critérios mais fundamentados em pressões políticas e de instituições, os governos deixam de fomentar o desenvolvimento de setores estratégicos para o desenvolvimento econômico e social do país. ${ }^{1}$ Outro argumento contrário à utilização das políticas industriais é que, em vista da cultura patrimonialista, ${ }^{2}$ ou seja, a tênue divisão que separa o que é público do que é privado em países como o Brasil, essas políticas colaboram para o aumento da corrupção, dos vícios públicos, da socialização dos prejuízos e dos benefícios privados.

Por isso, autores como Ferreira e Hamdan (2003) defendem o uso de políticas horizontais, tais como política fiscal austera; controle de inflação; incentivo à poupança; estabilidade econômica e política; defesa do direito à propriedade; sistema judiciário eficiente; redução dos custos de logística; educação e qualificação de mão de obra; programas visando medir a qualidade e a competitividade do setor industrial; regulação das concessões de serviços públicos e investimento em capital humano e infraestrutura. Resumindo, o uso de políticas horizontais não faz distinção dos setores que irão receber proteção por parte do governo, e ter uma economia com fundamentos macroeconômicos sólidos é a melhor maneira de o governo promover a competitividade do setor industrial.

Apesar das controvérsias que cercam o uso de políticas industriais, elas foram utilizadas por várias nações, especialmente em países da Europa, Estados Unidos e países asiáticos. A Inglaterra, desde a dinastia Tudor, no século XVI, utilizou-se de restrições às importações para proteger o setor manufatureiro. Tal política só foi abandonada no século XIX, quando sua liderança econômica já era incontestável (Chang, 2002). Todavia, foi na Alemanha que se originou o argumento da proteção industrial através das ideias de List, já destacadas neste trabalho. Esse país, além de subsídios e tarifas, utilizou-se de concessão de monopólios e intervenção do Estado nas indústrias-chave, para fomentar o desenvolvimento do setor industrial, conforme Irwin (1996).

A França, considerada o berço do liberalismo político e econômico, utilizou-se de vários mecanismos protecionistas para beneficiar sua indústria, sendo que, no período pré-Revolução Francesa, como forma de fomentar o setor industrial, incentivava a espionagem industrial e a recrutação de mão de obra qualificada ingle-

\footnotetext{
${ }^{1}$ Autores como Rodrik (2010) rebatem as críticas ao argumento de que política industrial é uma forma de os governos escolherem vencedores e deixarem de fomentar outros setores importantes para o desenvolvimento. Segundo o autor, o que determina o sucesso de uma política industrial não é a capacidade de escolher os vencedores, mas a capacidade de deixar os perdedores caírem fora, ou seja, um requisito menos exigente. Ainda neste contexto, incertezas asseguram que até mesmo políticas ótimas conduzem a erros, contudo o fundamental é que os governos percebam esses erros e retirem seu apoio antes que as políticas tornem-se muito dispendiosas.

${ }^{2}$ Para uma análise detalhada sobre o conceito de patrimonialismo, ver Faoro (2008).
} 
sa. No período pós-revolução, o país também continuou a utilizar mecanismos para proteger o setor secundário através de exposições industriais, criação de associações empresariais e invenção de máquinas (Chang, 2002).

Os Estados Unidos, logo após a Independência, concentraram o seu desenvolvimento em duas regiões, a Sul, escravocrata, e a Norte, que se balizou no setor industrial e defendia proteção ao setor através de restrição voluntária às importações, imposição de cotas e tarifas e sanções. As práticas protecionistas muito se devem a Alexander Hamilton, primeiro secretário do tesouro americano. Ele apregoava que a concorrência estrangeira e a força do hábito impediriam as novas indústrias que, em breve, poderiam ser competitivas internacionalmente, de se desenvolverem nos Estados Unidos, a menos que a ajuda governamental compensasse os prejuízos iniciais. De acordo com Chang (2002), é impossível subestimar a importância do protecionismo para o desenvolvimento do setor industrial norte-americano.

Os países asiáticos são os casos mais recentes do uso e do sucesso de políticas industriais, sendo que Japão, Coreia do Sul, Índia e China utilizaram diversas ações para proteger o setor industrial. De acordo com Bora et al. (2000), de maneira geral, todos os países asiáticos adotaram políticas industriais com instrumentos tais como restrição às importações, investimentos em setores estratégicos e em capital humano, créditos, subsídios e juros baixos ao setor industrial, investimento em infraestrutura e logística, criação e promoção de conglomerados econômicos e responsabilidade macroeconômica.

O Japão foi um dos países mais destruídos após a Segunda Guerra Mundial e, não obstante, na década de 1970, já se configurava como uma potência industrial. Para isso, entretanto, foram fundamentais ações estratégicas e uma combinação de políticas industriais e fiscais, que se utilizaram de instrumentos como redução de impostos sobre matérias-primas, política de ciência e tecnologia, investimento em capital humano, coordenação e cooperação entre os setores governamentais e industriais, austeridade fiscal com controle das taxas de inflação e do déficit público e políticas creditícias, com ênfase nos setores estratégicos para o desenvolvimento do país (Chang, 2002).

A Coreia do Sul, de acordo com Souza (2009), teve seu desenvolvimento econômico alicerçado na industrialização orientada para o mercado externo e, para o sucesso deste modelo, foi determinante a política industrial balizada em incentivos fiscais e financeiros, nos créditos de curto e longo prazos, nos juros baixos para as atividades industriais, em investimentos em indústrias exportadoras, controle de importações e ênfase no desenvolvimento de setores como ferro e aço, máquinas, metais não ferrosos, eletrônicos e petroquímicos.

A Índia, ao iniciar seu processo de industrialização, deu ênfase à indústria pesada e, posteriormente, priorizou setores estratégicos para o desenvolvimento do país, utilizando-se de altas tarifas de importação. A política industrial indiana, como forma de evitar a concentração industrial, foi alicerçada na ideia de descentralização, não se concentrando em poucos produtos, sendo que a ênfase atualmente está centrada nos bens de capital e produtos de alta tecnologia (Souza, 2009).

A política de desenvolvimento do setor industrial chinês utilizou-se de proteção 
à indústria, de reformas estruturais e fiscais, destacando-se investimentos em infraestrutura e logística, prioridade nas indústrias de bens de capital em vez de bens de consumo, investimento em ciência, tecnologia e capital humano, créditos e subsídios ao setor industrial, controle das taxas de inflação e dos déficits externo e público, restrições às importações através de cotas, subsídios e barreiras não tarifárias, dentre outros (Souza, 2009).

De acordo com Pinheiro et al. (2007), por mais que as políticas industriais dos países asiáticos se assemelhassem às de países como o Brasil, em aspectos como concessão de crédito e redução de tributos, a grande diferença entre ambas e que contribuiu para o sucesso destas políticas nos países asiáticos, está relacionada com instrumentos referentes à qualidade do ajuste fiscal, ao controle dos gastos públicos e das taxas de inflação, à qualidade da burocracia estatal, com combate à ineficiência e à corrupção no setor público, além de significativos investimentos em capital humano.

Nos países latino-americanos, como o Brasil, as políticas industriais começaram a ser utilizadas a partir de 1930, por meio do Modelo de Substituição de Importações, o qual visava proteger e fomentar o setor industrial.

\section{POLÍTICAS INDUSTRIAIS NO BRASIL}

No Brasil, a primeira tentativa de proteger a produção nacional, ${ }^{3}$ de forma coordenada, ocorreu no governo Vargas, no início da década de 1930, quando o governo passou a comprar o excedente de café do setor para depois destruí-lo. Além disso, de acordo com Peláez (1968), o governo Vargas criou um imposto em espécie de $20 \%$ sobre as exportações de café. Também foi criado um imposto de um mil-réis por novo cafeeiro plantado nos cinco anos subsequentes. Essas intervenções objetivavam sustentar as cotações internacionais do produto. Isso permitiu ao governo fazer a transferência de recursos para o setor industrial através de investimento em infraestrutura e proteção às indústrias que se consolidavam no país. De acordo com Bresser-Pereira (2012), essa estratégia utilizada por Vargas foi rotulada de protecionista pelos liberais e cafeicultores, contudo era uma forma de neutralizar um problema econômico que mais tarde se convencionou chamar de "doença holandesa" ${ }^{4}$ iniciar o processo de substituição de importações.

\footnotetext{
${ }^{3}$ Embora a maior parte dos economistas apregoe que o processo de industrialização iniciou-se com Vargas, em 1930, esta hipótese não é consensual na literatura econômica, e autores como Suzigan (1975), Silva (1995) e Cardoso de Mello (2009) consideram que o processo de industrialização iniciou-se em 1888 , com o fim da escravidão.

${ }^{4}$ De acordo com Bresser-Pereira (2012a), a doença holandesa ocorreu durante a década de 1960 naquele país, quando houve a descoberta de enormes reservas de gás de petróleo. Com o aumento das exportações de gás, a taxa de câmbio começou a se apreciar, de forma que, se nada fosse feito, o país iria trocar indústrias de alto conteúdo tecnológico pela produção de gás. Como forma de evitar isso, o governo criou um imposto sobre as exportações.
} 
Para Furtado (2001), o crescimento da industrialização, na década de 1930, foi subproduto da defesa do setor cafeeiro, ou seja, o governo não tinha a intenção de avançar com o processo de industrialização, mas, sim, evitar o aprofundamento da crise no setor. Fonseca (1989), por sua vez, ao analisar o governo de Vargas sob a ótica do pensamento institucionalista, ou seja, não se limitando às políticas monetárias e cambiais, mas analisando as instituições, órgãos criados e, principalmente, o discurso varguista, demonstra que Vargas certamente tinha uma consciência industrializante, a qual se materializou logo no começo de seu governo ao criar órgãos e institutos pró-industrialização. Nesse governo, além do início do processo de substituição de importações, tem-se também o delineamento de uma corrente política que vai marcar a história da política brasileira, ou seja, o nacional-desenvolvimentismo, entendido como defesa da industrialização; do intervencionismo pró-crescimento e do nacionalismo (Fonseca, 2010).

No primeiro governo Vargas (1930-1945), observa-se a criação de vários órgãos, legislações e medidas que irão fomentar o crescimento do setor industrial, tais como criação do Ministério do Trabalho, Indústria e Comércio, Instituto do Açúcar e do Álcool, Código de Minas, Código de Águas, Instituto Brasileiro de Geografia e Estatística (IBGE), Comissão de Defesa da Economia Nacional, Consolidação das Leis Trabalhistas, expansão do crédito, criação da Carteira de Crédito Agrícola e Industrial do Banco do Brasil e da Superintendência da Moeda e do Crédito (Sumoc). Em 1934, o governo fez uma reforma tributária que atendia a vários anseios da classe empresarial. Também merecem destaque as ações de cunho macroeconômico como desvalorização real da taxa de câmbio, controle de câmbio e a captação e distribuição de poupança (Ianni, 1979). O resultado dessas medidas e ações refletiu-se no crescimento do setor industrial, sendo que a média anual, de 1933 a 1939, foi de 8,4\%, enquanto, na indústria de transformação, a média anual de crescimento no período foi de $11,3 \%$.

Ao assumir a Presidência, pela segunda vez, Vargas deixou claras algumas ações que seriam foco de seu governo, tais como avançar com o processo de substituição de importações, até o momento concentrado nos bens de consumo não duráveis, e enfrentar a questão energética e dos transportes, setores detectados como gargalos para o crescimento econômico. ${ }^{5}$

Outro ponto que merece destaque nos dois governos Vargas é que, para viabilizar o processo de substituição de importações, o setor primário não foi excluído de medidas de incentivo, como crédito, posto que passou a ter novas funções, como produzir matérias-primas, ser mercado consumidor dos produtos industrializados, gerador de divisas para compra de máquinas e insumos necessários à indústria,

\footnotetext{
${ }^{5}$ Neste sentido, o governo criou os seguintes órgãos: Comissão de Desenvolvimento Industrial, Comissão de Coordenação e Desenvolvimento dos Transportes, Comissão Nacional de Bem-Estar, Comissão Executiva do Carvão Nacional, Banco do Nordeste, Banco do Crédito do Amazonas, Banco Nacional de Crédito Cooperativo e Banco Nacional do Desenvolvimento Econômico (BNDE). Além disso, como forma de resolver os problemas energéticos do país, foi criada a Petrobras e proposta a criação da Eletrobras (Fonseca, 1989).
} 
dentre outros (Souza \& Fonseca, 2009). Enfim, apesar das críticas e objeções ao governo Vargas, não se pode negar seu importante papel para o início do processo de industrialização no país.

Esse processo de substituição de importações foi acelerado no governo Juscelino Kubitschek (1956-1961), através de um planejamento com objetivos e metas mais coesos e organizados, com o slogan de fazer o Brasil crescer 50 anos em cinco anos de governo. Neste sentido, com base nos estudos do Banco Nacional de Desenvolvimento Econômico (BNDE) e da Comissão Econômica para a América Latina (Cepal), que identificaram os pontos de estrangulamento do país, ou seja, áreas de demanda insatisfeita devido às características desequilibradas em função do crescimento econômico, e os pontos de germinação, ou seja, áreas que geram demandas derivadas, o governo formulou o Plano de Metas (Ianni, 1979).

O Plano de Metas tinha como objetivos gerais investimentos em estatais, em infraestrutura, principalmente em transporte e energia elétrica; incentivo ao aumento da produção de bens de capital como máquinas e equipamentos e intermediários, tais como aço, carvão e zinco; incentivo à produção dos setores de bens de consumo duráveis; e estímulo à produção de alimentos (Fonseca \& Monteiro, 2008). O Plano de Metas constituía-se de cinco metas prioritárias, a saber: energia, transportes, alimentação, indústrias de base, educação, e a construção de Brasília seria a meta síntese.

Os recursos para financiar o plano seriam obtidos através de créditos, financiamentos e associação com o capital internacional. Os resultados foram extremamente significativos, visto que, de 1957 a 1960, foram fabricados 300 mil veículos; construídos mais de 20 mil km de rodovias e $800 \mathrm{~km}$ de ferrovias; a produção de aço foi dobrada, passando de um milhão de toneladas para 2 milhões por ano; a produção de petróleo alcançou o patamar de 30 milhões de barris por ano; o Produto Interno Bruto (PIB), de 1956 a 1960, cresceu 8,1\% ao ano, o PIB do setor industrial apresentou um crescimento de $10 \%$ ao ano no período. Além disso, destaca-se o aumento da participação do setor público no investimento fixo da economia, que passou de $27,5 \%$, no período $1950-1956$, para $37,1 \%$, no período 1957-1960, o que demonstra a importância do Estado para a consolidação do plano (Lessa, 1982).

Embora tenha apresentado resultados positivos, o plano gerou vários pontos negativos, tais como uma inflação média anual de $25 \%$, no período de 1956 a 1961 , aumento da dívida externa e das desigualdades sociais. De acordo com Brum (2005), o governo JK deixou uma "bomba" prestes a estourar no que tange à elevação da taxa de inflação. Os governos seguintes, de Jânio Quadros e João Goulart, além de não terem uma base política sólida, precisaram enfrentar vários problemas herdados da era JK, como aumento da inflação e crise cambial, ou seja, insolvência para atender os compromissos internacionais. O governo Goulart foi derrubado por um golpe de Estado, e assumiu o Marechal Castelo Branco, que lançou o Plano de Ação Econômica do Governo (PAEG), o qual visava combater a inflação e fazer reformas no setor monetário e financeiro (Brum, 2005).

Ao final do governo Castelo Branco, a inflação já estava controlada, as contas, 
equilibradas, e o país já tinha condições de crescer. Neste sentido, nos governos subsequentes, do Marechal Costa e Silva e do General Médici, a economia brasileira alcançou um crescimento extremamente significativo, contudo não se pode afirmar que estes governos tenham tido uma política industrial, o que só viria acontecer no governo Geisel (Ianni, 1979).

Em 1974, Geisel assume a Presidência para um mandato de cinco anos. Sua eleição e posse significavam a volta do grupo "castelista" ao poder, ou seja, os defensores de um regime autoritário mais moderado, que pregava uma abertura política lenta, segura e gradual. Ao assumir a Presidência, no campo econômico, Geisel tinha duas alternativas: fazer um ajustamento ou financiar o crescimento. A opção foi pela última hipótese, sendo lançado o II Plano Nacional de Desenvolvimento (II PND), que tinha por objetivo manter o crescimento econômico em torno de $10 \%$ a.a. e o crescimento do setor industrial em $12 \%$ a.a. Além disso, a ênfase do processo industrial seria nos bens de capital e nos insumos básicos, como produtos siderúrgicos e suas matérias-primas; metais não ferrosos; produtos petroquímicos; cimento; enxofre; e outros materiais não metálicos (Brasil, 1974).

Especificamente para fomentar o setor industrial, o governo propôs o desenvolvimento dos setores de base, especialmente bens de capital, tais como eletrônica e insumos básicos; abertura de novos campos de exportação de manufaturados; maior impulso ao desenvolvimento tecnológico nacional; desenvolvimento de projetos de exportação de matérias-primas; aumento da produção de petróleo e da capacidade de geração de energia hidrelétrica; desenvolvimento do transporte ferroviário e do sistema de telecomunicações; e atenuação dos desníveis regionais de desenvolvimento industrial (Gremaud \& Pires, 1999).

Para alcançar os objetivos elencados no II PND, o governo utilizou-se de transferência de parte da poupança privada, então destinada ao financiamento dos bens de consumo duráveis; obtenção de financiamento externo, atração de investimentos de risco sob a forma de joint verntures; investimentos em infraestrutura em setores estratégicos e reduções de tributos (Serra, 1982).

Devido à conjuntura internacional desfavorável, oriunda das crises do petróleo e do fim do Acordo de Bretton Woods, o II PND não obteve os resultados esperados, apesar do crescimento do PIB no período ser de 6,8\% a.a., o do setor industrial, de $6,5 \%$ a.a. e a formação bruta de capital fixo passar de 19,6\% em relação ao PIB, entre 1968 e 1973, para 22,7\% no período 1974-1979. Contudo, os maiores problemas deixados pelo plano foram o aumento da dívida externa, que passou de US\$ 7 bilhões, entre 1968 e 1973, para US\$ 31,6 bilhões entre 1974 e 1979; das desigualdades sociais e das taxas de inflação que, no final de 1979, eram de aproximadamente $80 \%$ ao ano (Carneiro, 2002). Quando se discutem os objetivos e ações do II PND, uma das questões levantadas por vários economistas refere-se à racionalidade do plano, visto que a conjuntura internacional já não era tão favorável para a atração de investimentos e financiamentos, e a questão que se coloca é se não seria mais racional o governo, em vez de financiar o crescimento econômico, fazer ajustes estruturais na economia.

$\mathrm{Na}$ década de 1980, que ficou conhecida como década perdida devido às altas 
taxas de inflação e baixo crescimento econômico, fenômeno conhecido como estagflação, o Brasil não adotou nenhuma política industrial, e o setor, desde então, começou a perder participação na formação do PIB. Em 1990, no governo Collor, foi decretado o fim do modelo de substituição de importações e da proteção ao setor industrial, promovendo-se a abertura unilateral da economia brasileira. Paralelamente, foram lançados os programas de privatização e desregulamentação e o Programa Brasileiro de Qualidade e Produtividade (PBQP), que objetivava analisar o desempenho do setor industrial brasileiro (Suzigan \& Furtado, 2006).

De acordo com Campanario e Silva (2004), de modo geral, as políticas industriais implantadas até as décadas de 1970 e 1980 tinham como objetivo gerar capacidade produtiva por meio de restrições às importações, estratégia que implicava baixa concorrência externa, baixa produtividade e adoção de padrões tecnológicos relativamente atrasados. Ou seja, estavam impregnadas de um viés protecionista.

\section{POLÍTICAS INDUSTRIAIS RECENTES NO BRASIL}

No governo Fernando Henrique Cardoso, a política industrial ficou subordinada à estabilidade econômica, ou seja, existia a convicção de que uma economia com sólidos fundamentos macroeconômicos era a condição necessária para alavancagem do setor industrial. ${ }^{6}$ Para Peres (2006), durante a década de 1990, na maioria dos países latino-americanos, a política industrial ficou sob a égide da política macroeconômica. Não obstante, alguns economistas, como Morais (2006), defendem que as ações do governo Fernando Henrique no Nordeste, para desenvolver o setor automotivo, através da discricionariedade de tributos, possam ser consideradas uma política industrial setorial, ainda que de caráter regional.

Em 2003, ao assumir a Presidência da República, Lula viu-se diante de vários desafios relacionados ao setor industrial, visto que, nos últimos anos, o setor passara por um processo de desaceleração. Isto pode ser corroborado pela baixa taxa média anual de crescimento (1,7\%) do setor industrial, de 1986 a 2002. Essa taxa foi bem inferior ao crescimento observado na década de 1970, que foi de, aproximadamente, 7,5\% a.a., conforme o Instituto Brasileiro de Geografia e Estatística - IBGE (2010).

Como forma de tentar aumentar a competitividade do setor industrial, o Governo Federal começou a montar, em 2003, as bases da Política Industrial, Tecnológica e de Comércio Exterior (PITCE), lançada em 2004. A PITCE focava em quatro eixos: (i) inovação e desenvolvimento tecnológico; (ii) inserção externa; (iii) modernização industrial e ambiente institucional e (iv) aumento da capacidade produtiva. As metas para o eixo inovação e desenvolvimento tecnológico objetivavam desenvolver a capacidade produtiva das empresas com o propósito de melhor inseri-las no mercado mundial. Além disso, visava-se dar diretrizes às parcerias

\footnotetext{
${ }^{6}$ Para uma análise mais acurada, ver Bresser-Pereira e Diniz (2009).
} 
públicas e privadas. Em relação à inserção externa, objetivava-se uma melhor inserção das indústrias brasileiras no comércio mundial, adequando-as às exigências dos principais mercados importadores. No que tange à modernização industrial, o destaque era a criação do Parque Industrial Nacional, com o objetivo de financiar a aquisição de novas máquinas e equipamentos nacionais. Por fim, no eixo ambiente institucional, o objetivo era melhorar a infraestrutura e reduzir tributos, sendo os setores-chave os semicondutores, os softwares, os bens de capital e os fármacos (Castilhos, 2005).

De acordo com Toni (2007), as principais diferenças da PITCE em relação a outras políticas industriais implantadas no país são a sinergia da política industrial com a de comércio exterior, o foco na inovação e os marcos legais e regulatórios propostos. Segundo Castilhos (2005), no entanto, a PITCE apresentou vários problemas, desde sua formulação, o que acabou fazendo com que essa política ficasse mais em propostas do que em ações concretas, merecendo destaque os seguintes aspectos: no que tange à inovação tecnológica, não apresentou incentivos ao desenvolvimento de tecnologias novas e adaptadas às necessidades das grandes indústrias brasileiras; na inserção externa, deixou de privilegiar setores com alto valor agregado; no setor de modernização industrial, não estavam claras as diretrizes e os objetivos desta modernização, além de não avançar na lei das patentes.

A PITCE não alcançou boa parte de seus objetivos devido, também, à falta de articulação e coordenação, proposição de ações mais horizontais que setoriais; pouca ênfase nos instrumentos fiscais e, principalmente, em face da conjuntura econômica desfavorável ao lançamento de uma política industrial (Suzigan \& Furtado, 2006). Ainda neste contexto, para Suzigan e Furtado (2010), os principais problemas da PITCE estavam relacionados à ausência de atuação sistêmica no conjunto das instituições; à complexidade da estrutura orgânica das instituições; e à necessidade de adequar a capacitação de técnicos das instituições da área aos novos requisitos da política industrial e tecnológica. De acordo com Cano e Silva (2010) e Morais e Lima Júnior (2010), o grande mérito da PITCE foi reintroduzir na agenda de políticas públicas o tema da política industrial como instrumento importante para o desenvolvimento econômico e social. Além disso, merece destaque, como consequência dessa política, a criação de marcos legais como a Lei da Inovação e da Biossegurança e as bases para a criação da Política de Desenvolvimento Produtivo (PDP).

A Política de Desenvolvimento Produtivo, ${ }^{7}$ lançada em maio de 2008, teve como objetivo geral propiciar o crescimento econômico do país, impulsionado pelo desenvolvimento industrial, obtendo resultados na geração de empregos e

\footnotetext{
${ }^{7}$ A Política de Desenvolvimento Produtivo (PDP) abrange 24 setores da indústria, a saber: Aeronáutico; Agroindústria; Bens de Capital; Bioetanol; Biotecnologia; Carnes; Celulose e Papel; Complexo Automotivo; Complexo de Defesa; Complexo de Serviços; Complexo da Saúde; Construção Civil; Couro, Calçados e Artefatos; Energia Nuclear; Higiene, Perfumaria e Cosméticos; Indústria Naval e de Cabotagem; Madeiras e Móveis; Mineração; Nanotecnologia; Petróleo, Gás e Petroquímica; Plásticos; Siderurgia; Têxtil e Confecções; e Tecnologia da Informação e Comunicação.
} 
aumento da competitividade, segundo o Ministério do Desenvolvimento Indústria e Comércio (Brasil, 2010a). A coordenação dessa política está a cargo do Ministério do Desenvolvimento Indústria e Comércio (MDIC) e sua concepção por um Conselho Gestor, formado por representantes da Casa Civil e dos Ministérios da Fazenda, Planejamento Orçamento e Gestão e Ministério da Ciência e Tecnologia.

O governo, ao lançar a PDP, o fez no momento em que a economia vinha apresentando crescimento do setor industrial, melhora na balança comercial e queda nas desigualdades econômicas. O objetivo era evitar cometer o mesmo erro da PITCE, a qual foi lançada quando a economia brasileira não apresentava ainda as condições de arcar com os custos de uma política industrial. Contudo, logo após a sua implantação, a economia brasileira foi afetada pela crise econômica mundial, o que fez que o governo acelerasse a implementação das medidas da PDP (Negri, 2009).

Os objetivos da PDP eram ampliar a capacidade de oferta; preservar a robustez do balanço de pagamentos; elevar a capacidade de inovação; e fortalecer as micro e pequenas empresas. $\mathrm{O}$ alcance destes objetivos dependia da ampliação do investimento fixo de 17,6\% do PIB em 2007 para $21 \%$ em 2010; do aumento dos investimentos em pesquisa e desenvolvimento para $0,65 \%$ do PIB; da ampliação da participação das exportações brasileiras nas exportações mundiais de $1,18 \%$ em 2007 para 1,25\% no final de 2010; e da ampliação em $10 \%$ o número de micro e pequenas empresas exportadoras (Brasil, 2010b).

As expectativas iniciais eram de que os principais resultados dessas medidas fossem obtidos até o final do governo Lula. Contudo, os prazos para atuação de uma política industrial devem ter continuidade, pois são necessários também projetos de mais longo prazo para áreas que necessitem de um maior tempo de articulação e maturação (Brasil, 2010b).

A Política de Desenvolvimento Produtivo contém medidas e ações que podem ser classificadas em quatro diferentes categorias: a) de desoneração e isenção tributária; b) de crédito e financiamento; c) regulatórias; e d) diversas, as quais são assim denominadas por falta de definição, ou por serem meras intenções ou diretrizes, ou ainda, por se tratar de constituição de grupos de trabalho e elaboração de relatórios.

O custo dessa política, entre reduções e isenções fiscais, investimentos, créditos e subsídios, é de, aproximadamente, R $\$ 484$ bilhões. No que se refere às medidas de créditos e financiamentos, os recursos são oriundos de linhas de créditos especiais do Banco Nacional de Desenvolvimento Econômico e Social (BNDES) e da Financiadora de Estudos e Projetos (FINEP).

Dos 24 setores alvos da PDP, merecem destaque as medidas elencadas na Tabela 1. De acordo com Ferraz (2009), os pontos positivos da PDP são a sinalização para a iniciativa privada do novo dinamismo que o governo quer dar ao setor industrial; o estímulo ao investimento, o qual possui o duplo efeito de ampliar a capacidade produtiva, considerando-se numa perspectiva keynesiana de gerar estímulos de demanda com efeitos multiplicadores para o resto da economia; incentivo aos gastos privados em pesquisa e desenvolvimento, através da redução dos 
custos financeiros decorrentes da incerteza associada ao processo inovador, o qual permite às empresas criar novos produtos e processos; e os incentivos às empresas com isenções e desonerações fiscais.

O grande problema para a implantação da PDP foi a definição dos setores que seriam beneficiados pela política, visto que a decisão final dependia de maior credibilidade e embasamento para justificar tais escolhas. Outra crítica está relacionada às alterações de alíquotas para vários setores, o que deveria ser feito por mudanças na estrutura tributária e não por renúncias específicas (Ferraz, 2009).

Tabela 1: Principais objetivos setoriais propostos pela

Política de Desenvolvimento Produtivo (PDP)

\begin{tabular}{|c|c|}
\hline Setores & Objetivos \\
\hline Complexo Automotivo & Consolidar e ampliar a participação do país na produção mundial. \\
\hline Bens de Capital & $\begin{array}{l}\text { Ampliar a competitividade e a inserção externa da indústria } \\
\text { brasileira. }\end{array}$ \\
\hline Têxtil e Confecções & Ampliar a competitividade e as exportações. \\
\hline Madeiras e Móveis & $\begin{array}{l}\text { Conquistar o mercado de móveis de alto padrão nos Estados Unidos } \\
\text { e na Europa e ampliar a participação de móveis em geral em novos } \\
\text { mercados, desenvolver os arranjos produtivos locais, aumentar a } \\
\text { competitividade e valorização do design brasileiro. }\end{array}$ \\
\hline Construção Civil & $\begin{array}{l}\text { Ampliar e modernizar o setor de construção civil com o objetivo de } \\
\text { reduzir o déficit habitacional. }\end{array}$ \\
\hline $\begin{array}{l}\text { Indústria Naval e de } \\
\text { Cabotagem }\end{array}$ & $\begin{array}{l}\text { Fortalecer a indústria naval a partir de encomendas do segmento } \\
\text { off-shore e de demandas de armação nacional, especialmente para } \\
\text { a cabotagem. }\end{array}$ \\
\hline $\begin{array}{l}\text { Couro, Calçados e } \\
\text { Artefatos }\end{array}$ & $\begin{array}{l}\text { Incorporar tecnologias estratégicas como nanotecnologia e } \\
\text { biotecnologia na cadeia produtiva. }\end{array}$ \\
\hline Plásticos & $\begin{array}{l}\text { Consolidar o Brasil como exportador de produtos com tecnologia } \\
\text { e valor agregado, aumentando a competitividade das indústrias de } \\
\text { transformados plásticos. }\end{array}$ \\
\hline Complexo Aeronáutico & $\begin{array}{l}\text { Ampliar a participação de aeronaves civis e de aeropeças nacionais } \\
\text { no mercado internacional e mundial. }\end{array}$ \\
\hline $\begin{array}{l}\text { Petróleo, Gás Natural e } \\
\text { Petroquímica }\end{array}$ & $\begin{array}{l}\text { Garantir a autossuficiência de petróleo, revitalizar e ampliar a } \\
\text { participação da indústria nacional, em bases competitivas e } \\
\text { sustentáveis. }\end{array}$ \\
\hline $\begin{array}{l}\text { Celulose e Papel, } \\
\text { Mineração e Siderurgia }\end{array}$ & $\begin{array}{l}\text { A política objetiva consolidar a liderança competitiva por meio } \\
\text { de ampliação do porte empresarial, aumento da capacidade } \\
\text { tecnológica e fortalecimento das redes de logística e de } \\
\text { fornecimento de insumos. }\end{array}$ \\
\hline
\end{tabular}

Fonte: Organizada pelos autores, a partir de Brasil (2010a) e ABDI (2010).

Coronel et al. (2011) estimaram, através do Modelo de Equilíbrio Geral Computável - GTAPinGAMS, os efeitos da PDP sobre os setores produtivos que seriam 
beneficiados por esta política. Os resultados indicam que a política contribuiu para o aumento da produção e das exportações e queda das importações dos setores de baixa e média intensidade tecnológica, com destaque para o setor Automotivo e de Bens de Capital. Ainda, segundo esse estudo, esta política mostrou-se ineficaz para os setores de alta intensidade tecnológica, visto que as medidas adotadas para estes setores não conseguiram colaborar para o aumento da produção e das exportações e quedas nas importações.

Bresser-Pereira (2013), baseando-se nos pressupostos do novo desenvolvimentismo, enfatiza que uma política macroeconômica que privilegie o equilíbrio fiscal, taxas de juros relativamente baixas e, especialmente, uma taxa de câmbio competitiva seria, inclusive, mais importante do que a própria política industrial para garantir competitividade às empresas que atuam no país. No que se refere especificamente ao câmbio, o autor ressalta a sua importância para neutralizar os efeitos da doença holandesa. Uma política cambial que evitasse a apreciação da moeda local teria um papel crucial para evitar a perda de competitividade do setor industrial. Sob a égide do novo desenvolvimentismo, a política industrial deveria servir somente para estimular aqueles setores potencialmente competitivos internacionalmente e de modo provisório. Isso representaria um avanço em relação à política industrial do que o autor chama de velho desenvolvimentismo.

\section{CONCLUSÕES}

A Política Industrial é um tema controverso na literatura econômica, conforme demonstrado neste trabalho. Para economistas de cunho heterodoxo, as políticas industriais são importantes para o desenvolvimento, pois contribuem para a superação dos entraves ao crescimento industrial. Os instrumentos que o Estado pode utilizar para a promoção de tais políticas podem ser subsídios, créditos, isenções ficais, melhor infraestrutura e logística, aumento de barreiras às importações, políticas de desenvolvimento tecnológico e de inovação.

De modo geral, os autores de cunho neoclássico são contrários ao uso de tais políticas, principalmente em países como o Brasil, pois, além de o Estado escolher os setores que serão vencedores, colaboram para o aumento dos vícios públicos e dos benefícios privados. De acordo com esta visão, as políticas industriais só devem ser utilizadas com o objetivo de corrigir falhas de mercado. Assim, a melhor forma de o governo proteger o setor industrial é através de políticas horizontais, tais como política fiscal austera, controle das taxas de inflação, estímulo à concorrência e sistema judiciário eficiente.

Embora as políticas industriais recebam várias críticas, inúmeros países desenvolvidos utilizaram deste instrumental. No Brasil, as políticas industriais só começaram a ser utilizadas em 1930, quando o governo Vargas comprou o excedente do setor cafeeiro e criou um imposto sobre as exportações do setor. Mais tarde, estabeleceram-se novas instituições voltadas à industrialização, as quais corroboraram gradativamente para a mudança do centro dinâmico da economia. Poste- 
riormente, na segunda metade da década de 1950, o governo Kubitschek, com a implantação do Plano de Metas, adotou uma ação coordenada pelo Estado com o objetivo de mudar a estrutura industrial brasileira.

A terceira tentativa de fomentar o setor industrial com certa coordenação ocorreu no governo Geisel, quando do lançamento do II Plano Nacional de Desenvolvimento, com o objetivo de manter as taxas de crescimento do setor industrial em $12 \%$ a.a. Devido à conjuntura econômica internacional desfavorável, o governo não conseguiu manter as taxas de crescimento, apesar de ter conseguido taxas de crescimento do setor industrial de $6,5 \%$ a.a.

$\mathrm{Na}$ década de 1980, o Brasil não adotou nenhuma política industrial devido à grave crise econômica do país. Com o governo Collor, o Brasil promoveu uma abertura unilateral da economia e criou programas para avaliar a competitividade do setor industrial. O governo Fernando Henrique adotou a concepção de que uma política econômica com sólidos fundamentos macroeconômicos seria a melhor maneira para o Estado contribuir para o crescimento industrial.

O governo Lula lançou, em 2004, a Política Industrial, Tecnológica e de Comércio Exterior (PITCE) com o objetivo de fomentar o setor industrial, mas, por falta de objetivos bem definidos e pela conjuntura econômica desfavorável, esta política não apresentou os resultados esperados. Em 2008, como uma nova tentativa de fomentar o setor industrial, foi lançada a Política de Desenvolvimento Produtivo (PDP), a qual não conseguiu atingir boa parte de suas metas muito em função da falta de critérios, objetivos dos setores que seriam estratégicos para o melhor desenvolvimento e uma maior inserção do setor industrial brasileiro.

De modo geral, este artigo demonstrou que as políticas industriais adotadas no Brasil, ao longo do tempo, têm apresentado um viés protecionista e exigido poucas contrapartidas de seus beneficiários. Apesar do forte estímulo que concedeu ao setor industrial brasileiro, especialmente entre 1930 e 1980, há a sensação de que as suas velhas fórmulas não devem ser repetidas no futuro. Uma alternativa seria a adoção de políticas baseadas no novo desenvolvimentismo proposto por Bresser-Pereira (2013). Os benefícios deveriam ser temporários e atuar somente em setores em que o país é potencialmente competitivo internacionalmente. Para aumentar as suas chances de sucesso, deveriam ser coordenadas com uma política macroeconômica que buscasse o equilíbrio fiscal, taxas de juros relativamente baixas e, especialmente, uma taxa de câmbio competitiva.

\section{REFERÊNCIAS BIBLIOGRÁFICAS}

AGÊNCIA BRASILEIRA DE DESENVOLVIMENTO INDUSTRIAL - ABDI. (2010). Disponível em: $<$ http://www.abdi.com.br/?q=node/3>. Acesso: em $18 \mathrm{dez}$.

BORA, B.; LLOYD, P.J.; PANGESTU, M. (2000). Industrial policy and the WTO. The World Economy, v. 23, n. 4, p. 543-559.

BRASIL. (1974). II Plano Nacional de Desenvolvimento (1975-1979). Brasília.

BRASIL. (2010a). Ministério do Desenvolvimento, Indústria e Comércio. Política de Desenvolvimento 
Produtivo (PDP). Disponível em: <http://www.mdic.gov.br/pdp/ index. php/sitio/inicial>. Acesso em: 4 ago.

BRASIL. (2010b). Ministério do Desenvolvimento, Indústria e Comércio. Comércio exterior. isponível em: <http://www.mdic.gov.br/pdp/index. php/sitio/inicial>. Acesso em: 4 set.

BRESSER-PEREIRA, L. C. (2009). Globalização e competição: porque alguns países emergentes têm sucesso e outros não. Rio de Janeiro: Elsevier.

BRESSER-PEREIRA, L.C. (2010). Desindustrialização e câmbio. Disponível em: <http://www.bresserpereira.org.br/Papers/Interviews/2010/10.09.Entrevista_Bresser-NI.pdf.> Acesso em: 14 out., 2010.

BRESSER-PEREIRA, L.C. (2011) A taxa de câmbio no centro da teoria do desenvolvimento. 2011. Disponível em:

http://www.bresserpereira.org.br/papers/2011/11.24.Macro_cambio_teoria_desenvolv_n_destin.pdf. Acesso em: 3 jan. 2012.

BRESSER-PEREIRA, L.C. (2012a). Getúlio Vargas: o estadista, a nação e a democracia. In: BASTOS, P.P.Z.; FONSECA, P.C.D. (Org.) A Era Vargas: desenvolvimentismo, economia e sociedade. São Paulo: Editora Unesp.

BRESSER-PEREIRA, L.C. (2012b). Structuralist Macroeconomics and the new developmentalism. Revista de Economia Política, v. 32 n. 3, p. 347-366.

BRESSER-PEREIRA, L. C.; DINIZ, E. (2009). Empresariado industrial, democracia e poder político. Novos Estudos CEBRAP, v. 38 n. 1, p. 83-100, 2009.

BRUM, A.J. (2005). Desenvolvimento econômico brasileiro. 24. ed. Petrópolis: Vozes.

CAMPANARIO, M.D.A.; SILVA, M.M.D. (2004). Fundamentos de uma nova política industrial. In: FLEURY, M.T.L.; FLEURY, A. Política industrial. São Paulo: Publifolha.

CANO, W.; SILVA, A.L.G. (2010). Política industrial do governo Lula. Campinas: IE/UNICAMP, (Texto para discussão, 181).

CARDOSO DE MELLO, J.M. (2009). O capitalismo tardio. 11. ed. São Paulo: UNESP.

CARNEIRO, R. (2002). Desenvolvimento em crise: a economia brasileira no último quartel do século XX. São Paulo: UNESP-IE-UNICAMP.

CASTILHOS, C. C. (2005). Contradições e limites da política industrial do Governo Lula. Indicadores Econômicos (FEE), Porto Alegre, v. 33, n. 1, p. 54-74.

CHANG, H.J. (2002). Kicking away the ladder: development strategy in historical perspective. Londres: Anthem Press.

CORONEL, D. A. et al. (2011). Impactos da política de desenvolvimento produtivo na economia brasileira: uma análise de equilíbrio geral computável. Pesquisa e Planejamento Econômico, Rio de Janeiro, v. 41, n. 2, p. 337-365.

FAORO, R. (2008). Os donos do poder: formação do patronato político brasileiro. 4. ed. São Paulo: Globo.

FERRAZ, M.B. (2009). Retomando o debate: a nova política industrial do governo Lula. Planejamento e Políticas Públicas, Brasília, v. 32, n. 2, p. 227-263.

FERREIRA, P.C.; HAMDAN, G. (2003). Política industrial no Brasil: ineficaz e regressiva. Econômica, Rio de Janeiro, v. 5, n. 2, p. 305-316.

FONSECA, P.C.D. (1989). Vargas o capitalismo em construção. São Paulo: Brasiliense.

FONSECA, P.C.D. (2010). Nem ortodoxia nem populismo: o segundo governo Vargas e a economia brasileira. Tempo-Revista do Departamento de História da UFF, Rio de Janeiro, v. 14, p. 19-58.

FONSECA, P. C.D.; MONTEIRO, S.M.M. (2008). O Estado e suas razões: o II PND. Revista de Economia Política, São Paulo, v. 28, n. 1, p. 28-46.

FURTADO, C. (2001). Formação econômica do Brasil. 30. ed. São Paulo: Nacional.

GREENAWAY, D.; MILNER, C. (1993). Trade and industrial policy in developing countries: a manual of policy analysis. Hampshire: The Macmillan Press.

GREMAUD, A.P.; PIRES, J.M. (1999). II Plano Nacional de Desenvolvimento (1975-1979). In: KON, A. (Org.). Planejamento no Brasil. São Paulo: Perspectiva. 
IANNI, O. (1979). Estado e planejamento econômico no Brasil: 1930-1970. 3. ed. Rio de Janeiro: Civilização Brasileira.

INSTITUTO BRASILEIRO DE GEOGRAFIA E ESTATÍSTICA - IBGE. (2010). Economia. Disponível em:

http://www.ibge.gov.br/home/mapa_site/mapa_site.php\#economia>. Acesso em: 10 jan.

IRWIN, D. (1996). Against the tide: an intellectual history of free trade. New Jersey: Princeton University Press.

KRUGMAN, P.R. (1989). Industrial organization and international trade. In: SCHMALENSEE, R.; WILLIG, R. (Eds.). Handbook of industrial organization. New York: Elsevier.

KUPFER, D. (2003). Política industrial. Econômica, Rio de Janeiro, v. 5, n. 2, p. 281-298.

LESSA, C. (1982). Quinze anos de política econômica. 3. ed. São Paulo: Brasiliense.

LIST, F.G. (1986). Sistema nacional de economia política. São Paulo: Abril Cultural.

MILL, J.S. (1996). Princípios de economia política. São Paulo: Nova Cultural.

MORAIS, J.M.L. (2006). Mudança institucional e desenvolvimento: uma abordagem institucional-evolucionária da política industrial do estado do Ceará. 2006. Tese (Doutorado em Economia) Universidade Federal do Rio de Janeiro, Rio de Janeiro, RJ.

MORAIS, J.M.L.; LIMA JÚNIOR, F.D.O. (2010). Política industrial do Governo Lula: desenvolvimentista ou corretiva de falhas de mercado. In: ENCONTRO REGIONAL DE ECONOMIA, 15, 2010, Fortaleza. Anais... Fortaleza: ANPEC-NORDESTE, p. 1-20.

NEGRI, F.D. (2009). Diagnóstico recente da política de desenvolvimento produtivo. In: CARDOSO JÚNIOR, J.C. Brasil em desenvolvimento estado planejamento e políticas públicas. Brasília: IPEA.

PACK, H.; SAGGI, K. (2006). Is there a case for industrial policy? A critical survey. The Word Banck Research Observer, v. 21, n. 2, p. 267-297.

PELÁEZ, Carlos M (1968). A balança comercial, a grande depressão e a industrialização brasileira. Revista Brasileira de Economia, v. 2, n. 1, p. 15-47.

PERES, W. (2006). The slow comeback of industrial policy in Latin America and the Caribbean. CEPAL Review, Chile, v. 88, n. 1, p. 71-88.

PINHEIRO, M.C. et al. (2007). Por que o Brasil não precisa de política industrial. Rio de Janeiro: FGV, (Texto para discussão, 644).

RODRIK, D. (2010). A volta da política industrial. Disponível em: $<$ http://www. jornaldaciencia.org. br/index2.jsp>. Acesso em: 25 ago.

SERRA, J. (1982). Ciclos e mudanças estruturais na economia brasileira de após-guerra: a crise recente. Revista de Economia Política, São Paulo, v. 2, n. 3, p. 111-135.

SILVA, S. (1995). Expansão cafeeira e origens da indústria no Brasil. 8 ed. São Paulo: Editora Alfa-Omega.

SOUZA, N.D.J. (2009). Desenvolvimento econômico. 5. ed. São Paulo: Atlas.

SOUZA, L.E.S.D.; FONSECA, P.C.D. (2009). O processo de substituição de importações. São Paulo: LTCE.

SUZIGAN, W. (1975). Industrialização e política econômica: uma interpretação histórica. Pesquisa e Planejamento Econômico, Rio de Janeiro, v. 5, n. 2, p. 433-474.

SUZIGAN, W.; FURTADO, J. (2006). Política industrial e desenvolvimento. Revista de Economia Política, São Paulo, v. 26, n. 2, p. 163-185.

SUZIGAN, W.; FURTADO, J. (2010). Instituições e políticas industriais e tecnológicas: reflexões a partir da experiência brasileira. Estudos Econômicos, São Paulo, v. 40, n. 1, p. 7-41.

TONI, J. D. (2007). Novos arranjos institucionais na renovação da política industrial brasileira. Ensaios FEE, Porto Alegre, v. 28, n. 1, p. 127-158. 